\title{
El patrimonio cultural en la normativa municipal de Comodoro Rivadavia, Argentina (1985-2016)
}

\author{
The cultural heritage in the municipal laws of \\ Comodoro Rivadavia, Argentina (1985-2016) \\ Graciela Ciselli ${ }^{\mathrm{a}}$, Marcelo Hernández ${ }^{\mathrm{b}}$ \& Antonella DuplatT $^{\mathrm{c}}$ \\ a Doctora en Ciencias Jurídicas y Sociales \\ Universidad Nacional de la Patagonia San Juan Bosco \\ ${ }^{\text {b }}$ Licenciado en Comunicación Social. Maestrando en Estudios socio-territoriales. \\ Docente Universidad Nacional de la Patagonia San Juan Bosco. \\ c Abogada. Maestranda en Administración de Organizaciones Culturales y Creativas. \\ Docente Universidad Nacional de la Patagonia San Juan Bosco. \\ graciselli@hotmail.com; mar30hernandez@gmail.com; antoduplatt@gmail.com
}

\section{RESUMEN}

En Argentina el reconocimiento del patrimonio cultural como derecho constitucional generó responsabilidades de preservación para las comunidades y el Estado. En 1985 el municipio de Comodoro Rivadavia elaboró su primera normativa patrimonial que fue actualizada y ampliada entre 2014 y 2016 a partir de acciones de vecinos que le reclamaban porque se veía "afectada su calidad de vida y su patrimonio cultural”. El artículo aborda los avances en el régimen jurídico del patrimonio cultural municipal teniendo en cuenta los instrumentos internacionales y nacionales y la actuación de los actores no estatales. Para el análisis se optó por un abordaje hermenéutico que contempla la normativa vigente de un modo integral que, complementado con un enfoque etnográfico, permitió indagar en la apropiación de la normativa por parte de la comunidad local.

PALABRAS CLAVE: patrimonio cultural, municipio, derechos, Patagonia.

\begin{abstract}
In Argentina, the recognition of cultural heritage as a constitutional right generated preservation responsibilities for the communities and the State. In 1985, the municipality of Comodoro Rivadavia prepared its first patrimonial regulations that were updated and expanded between 2014 and 2016, based on the actions of neighbors who complained that




\section{G. CISELLI et al.}

"their quality of life and cultural heritage was affected". The article addresses the advances in the legal regime of municipal cultural heritage taking into account international and national instruments and the action of non-state actors. For the analysis, a hermeneutic approach was chosen that contemplates the current regulations in an integral way that, complemented by an ethnographic approach, allowed us to investigate the appropriation of the regulations by the local community.

KEY WORDS: Cultural heritage, Municipality, rights, Patagonia.

\section{INTRODUCCIÓN}

Las últimas décadas del siglo XX coinciden con el interés de diversas instituciones, gubernamentales y no gubernamentales, en revalorizar bienes que integran el patrimonio cultural porque quienes intervienen en sus propuestas -políticos y administraciones públicas, académicos, expertos y vecinos- les atribuyen diversos usos: como recurso económico, como factor de cohesión social, como recurso político, identitario (Pérez Galán, 2011), factor dinamizador de las economías locales y generador de nuevos ingresos.

En Argentina, el reconocimiento otorgado al patrimonio cultural desde un enfoque de derechos humanos lo ha colocado en un lugar privilegiado de tutela con responsabilidades para el Estado y para los ciudadanos. En este trabajo interesa conocer la evolución normativa vigente tendiente a la preservación del patrimonio cultural en los diversos niveles de gobierno para profundizar en el marco jurídico municipal de Comodoro Rivadavia que incide en el tratamiento del Patrimonio Industrial local y regional.

La posibilidad de ejercicio real de los derechos consagrados fue puesta a prueba por actores no estatales que mediante acciones colectivas de diversa índole (movilizaciones, volantes, juntada de firmas, notas en los diarios) actuaron frente al Estado Municipal que no sólo retrocedió en aquellas decisiones que podían afectar la calidad de vida y el patrimonio de la ciudad, sino que actuó positivamente al sancionar tres Ordenanzas, abriendo un nuevo campo de acción para los ciudadanos en torno a la preservación del patrimonio cultural de su microterritorio. La apropiación de la normativa por parte de quienes habitan la ciudad forma parte de los desafíos a los que se ha sometido el Estado a partir del reconocimiento de sus autonomías municipales.

El artículo aborda la actuación del Estado teniendo en cuenta los compromisos asumidos en el sistema interamericano de derechos humanos sin descuidar el lugar otorgado a las comunidades en la defensa de los bienes colectivos. Para ello se responderán los siguientes interrogantes ¿Cómo se logra la operatividad del derecho al patrimonio cultural en el ámbito municipal? ¿Qué desafíos implica, tanto para los actores estatales como no estatales, reconocer al patrimonio como recurso cultural/identitario, pero también como recurso económico/turístico local? 


\section{Patrimonio Cultural: Una noción en constante revisión}

El concepto patrimonio cultural ha tenido su propio recorrido por diversas disciplinas formando parte de un campo de estudio históricamente discutido por arquitectos y urbanistas y en menor medida por historiadores, antropólogos, geógrafos y comunicadores sociales. Para los juristas argentinos la noción patrimonio cultural vinculada a la identidad de los pueblos y la calidad de vida constituye un desafío desde la Reforma constitucional de 1994.

Cuando se plantea el patrimonio como recurso cultural, se alude a una construcción social e histórica, que es disputada por grupos, y justificada discursivamente como referente de identidades sociales, territoriales, políticas, étnicas, etc., a partir de una selección que un grupo realiza dentro de una cultura que, luego de un proceso de patrimonialización, es reconocido y declarado formalmente como tal.

Lo declarado patrimonio puede no ser representativo de toda la comunidad sino el resultado de la lucha por la hegemonía cultural, política e histórica en cada región. Por lo tanto, hay que reconocer que existen tensiones entre lo propuesto, lo declarado y lo que la gente considera que es patrimonio pues los actores estatales como no estatales poseen una visión particular sobre el patrimonio y los modos de protegerlo o de atender la demanda ante nuevas acciones de patrimonialización. Esto nos lleva a repensar la dimensión política del patrimonio y de qué manera las concepciones de patrimonio interfieren en la gestión sobre el mismo y en las políticas públicas más convenientes para su conservación, activación, difusión (Ciselli, 2015).

Es decir que, el patrimonio es valorado como recurso cultural/identitario, pero también como recurso económico/turístico, lo que supone conflictos y riesgos en torno a su preservación. Ello debe ser considerado por los gobiernos locales al definir proyectos que pueden tener consecuencias ambientales, sociales o patrimoniales. Justamente las acciones de patrimonialización afloran en épocas de crisis -por ejemplo, si se trata de un edificio porque están por demolerlo, si es un bien público porque se lo está por negociar- para contraerse cuando pasan. García Canclini (1993) nos advierte que estos movimientos empiezan a modificar la agenda pública al hacer visible el tema patrimonial y mostrar que su cuidado, su conservación y su apropiación por parte de las comunidades que lo defienden y protegen, es tan necesaria como la generación normativa protectora por parte de los gobiernos.

En los últimos años otra categoría ha cobrado visibilidad: patrimonio industrial, asociada a la huella de una trama sistémica que forma parte de la ciudad y su territorio. Una trama que reconoce aspectos ambientales, sociales y culturales del patrimonio industrial (Rodríguez, 1998) y que al articularlos cargan de significación y simbolismo al territorio, es decir, lo van dotando de valor (Navarro Bello, 2003). Como categoría integral, la valoración de un conjunto industrial comprende tanto su materialidad como las experiencias colectivas y su valor testimonial. La Carta de Nizhny Tagil sobre Patrimonio Industrial, Rusia, 2003, ТІССIH, lo define como "los restos de la cultura industrial con valor histórico, tecnológico, 
G. CISELLI et al.

social, arquitectónico o científico. Son los edificios y las maquinarias, los talleres y sitios para procesar y refinar, almacenes y depósitos, medios de transporte y toda su infraestructura; como así también los sitios donde se desarrollan actividades sociales asociadas como vivienda, culto religioso, educación, recreación" (p.1).

Más allá de los criterios de valoración planteados por el soft law o derecho blando proveniente de las Cartas y las Recomendaciones o de las Convenciones y Protocolos que son vinculantes, existen tres atributos que son claves a la hora de considerar el patrimonio cultural.

El Patrimonio Cultural y sus atributos

a) El fortalecimiento de las identidades socio-territoriales

La defensa del patrimonio se vincula estrechamente con las identidades sociales que emergen cuando, por ejemplo, los residentes de un barrio se identifican con ese microterritorio dentro de la macro unidad que constituye la ciudad y se diferencian respecto del resto (Gravano, 2013) introduciéndole valores.

La identidad barrial se construye social e históricamente representando una forma de clasificación que crea una pertenencia, un modo de reconocimiento social que surge en la interacción cotidiana en un territorio y que se activa en confrontación con otro o con otros. Cada atributo del pasado se puede convertir en un valor distintivo del barrio. La identidad se construye por pertenecer a ese "antes" del barrio, a una época que sirve para homogeneizar el barrio (p.e. el barrio ypefeano).

b) Su valor como recurso cultural y turístico

Cuando se lo considera como capital que produce valor cultural y económico se lo asocia al conjunto de rentas que genera su propia existencia (valor de los edificios, obras de arte, entre otros), así como al flujo de bienes y servicios que puede dar lugar (usos e impacto sobre el turismo, productos y servicios, empleo).

Por lo tanto, es necesaria una evaluación de los beneficios que este produce tanto económicos como culturales y de sus potenciales beneficiarios. Throsby (2001, p. 91) divide los beneficios del "proyecto patrimonial" en valores de uso (del bien en sí), valores independientes del uso (por su mera existencia, la decisión de consumirlo o no, y la posibilidad de legarlo) y externalidades (se tiene en cuenta el coste-beneficio de un proyecto de patrimonio según los períodos temporales). El valor cultural del patrimonio que incide sobre el económico se relaciona con lo estético, lo espiritual, lo social (identitario), lo histórico y lo simbólico.

Otra arista la aporta Delgadillo Polanco (2010) quien explica que "los valores económicos se construyen en el mercado, mientras que los valores culturales se definen en la esfera de 
las relaciones sociales, se establecen en función de significados colectivos, y son difíciles de conceptuar y complicados de medir" (p. 387). Por lo tanto, para este autor, que una obra tenga mayor valor que otra en razón de sus cualidades "demuestra que esos son juicios de valor que varían entre los individuos, en el tiempo y en diferentes contextos sociales y políticos" (p. 387). A modo de ejemplo está el arte contestatario que, rechazado en su origen, luego se transformó en objeto de culto. Es decir que se debe tener en cuenta el contexto de creación, de generación de identidad, permanencia, historia local y grupo social. Además, en la consideración del valor se encuentra el precio que la gente está dispuesta a pagar por un bien que tal vez ni conoce o no se identifica.

Al tratarse de un recurso fijo cuyos bienes son únicos y no tienen valor en sí mismos, sino por las rentas que procuran los servicios derivados de él, el Estado tiene la obligación de su regulación, protección y financiación. Es decir, que tanto el valor cultural como económico justifican su cuidado. El desafío está en descubrir si es patrimonializable o no en términos de lo que significa para una comunidad en general como recurso cultural o turístico (Prats, 2006).

En el caso del patrimonio industrial, los valores a estimar están establecidos en el art. 2 de la Carta Nizhny Tagil. Ellos son:

- Universal: La evidencia de actividades que han tenido, y aún tienen, profundas consecuencias históricas, más que en la singularidad de sitios peculiares.

- Social: como parte del registro de vidas de hombres y mujeres corrientes, y como tal, proporciona un importante sentimiento de identidad.

- Tecnológico y científico: En la historia de la producción, la ingeniería, la construcción.

- Estético: la calidad de su arquitectura, diseño o planificación.

Estos valores son intrínsecos del mismo sitio, de su entramado, de sus componentes, de su maquinaria y de su funcionamiento, en el paisaje industrial, en la documentación escrita, y también en los registros intangibles almacenados en los recuerdos y las costumbres de las personas. La rareza, en términos de supervivencia de procesos particulares, tipologías de sitios o paisajes, añade un valor particular y debe ser evaluada cuidadosamente.

En el caso chubutense, el municipio de Comodoro Rivadavia creó por Ordenanza N 6629/1999 el Registro Permanente de Edificios, Sitios y Objetos del Patrimonio Histórico, Cultural y Natural de Comodoro Rivadavia. En ella se definen los valores culturales a tenerse en cuenta al momento de incorporar dichos bienes al Registro Permanente. Ellos son:

- Histórico: que refiere a los elementos testimoniales de una organización social o forma de vida que configuran la memoria histórica colectiva y un uso social actual. Abarca áreas, edificios, sitios u objetivos que han sido escenario o elementos 


\section{G. CISELLI et al.}

participantes de hechos claves de la historia de la ciudad o que han pertenecido a las personalidades relevantes que la protagonizaron. Asimismo, se evalúa el grado de participación en hechos claves de la historia de la ciudad (valor histórico); el autor; la representatividad que el sitio, edificio, u objetivo tiene al respecto de la comunidad en que está inserto, como representativo de una época, no necesariamente antigua, y de sus costumbres (valor simbólico); las cualidades del objeto como representante de determinadas circunstancias, épocas o movimientos artísticos y de su capacidad para comunicarlo (valor testimonial);

- Artístico arquitectónico: Este incorpora otros valores como el arquitectónico, el estético, el estado de conservación, el grado de exclusividad y el grado de riesgo.

- Natural: Este incorpora el paisajístico ambiental, el ambiental vinculado al edificio o sitio, y el de agrupamiento respecto de otros edificios de alto valor o de conjuntos homogéneos.

- Contextual: relación edificio- entorno, el grado de adaptabilidad del edificio, del entorno, el grado de degradación y el análisis de los componentes: su estado, su factibilidad de uso y reciclaje y el nivel de inversiones necesarias para su puesta en valor.

Esto permite elaborar un registro que contemple el tratamiento dado a los bienes y los criterios de valoración para realizar acciones tendientes a la conservación, defensa y puesta en valor de los bienes patrimoniales por parte del Estado municipal o de los propietarios de los bienes dependiendo de la titularidad del mismo. Como fue mencionado, los bienes del patrimonio son un recurso fijo por cuanto no son renovables. Por esta razón se debe asegurar la preservación de la herencia cultural para el disfrute de las generaciones presentes y futuras.

Krebs y Schmidt-Hebbel (s/f) explican que, aunque el valor económico sea importante para determinar la importancia de preservar un bien cultural, "el valor social o cultural que estos bienes tienen para un individuo, comunidad, nación y, en algunos casos, para la humanidad" (p. 209) son los que verdaderamente justifican su cuidado. El desafío está en descubrir si es patrimonializable o no en términos de lo que significa para una comunidad en general, en término de recurso cultural o turístico, y no sólo para un pequeño grupo.

El consumo de bienes culturales tangibles, a partir de su conservación, protección y refuncionalización deviene en el uso y goce de los bienes culturales por individuos o comunidades, su puesta a disposición para la investigación y su utilización como insumo para la educación y cultura. La demanda por bienes culturales engloba las demandas de los distintos grupos sociales y de agentes culturales.

En ese sentido, el turismo resulta una alternativa de fomento de la actividad y desarrollo económico local ya que genera beneficios en las economías locales como la creación de empleo, aumenta la inversión, incrementa los ingresos del sector público y revaloriza el 
patrimonio, vinculándose con las externalidades antes mencionadas, tal como resaltan los estudios de turismo local sobre "pueblos forestales" (Brac, 2011) o sobre "pueblos petroleros y ferroviarios” (Ciselli \& Duplatt, 2006; Figueroa \& Galleguillo, 2015).

La construcción del destino turístico y la elaboración de circuitos turísticos con el propósito de agregar alternativas a las propuestas de ocio, basadas en la posibilidad de proyectar el lugar como un atractivo turístico permite que el pasado se haga conocido por medio del patrimonio industrial. La revalorización del patrimonio está vinculado a nuevas maneras de hacer turismo y, en el proceso de patrimonialización, a la dimensión consumo. Prats (2006) distingue dos tipos de consumo turístico: uno patrimonial (también denominado turismo cultural) y el otro que efectúa visitas a activaciones patrimoniales (museos, exposiciones) como complemento de compras en un destino.

c) La calidad de vida como compromiso intergeneracional

Desde la Declaración de la Conferencia de las Naciones Unidas sobre el Medio Humano en 1972 se reconoce que "el hombre es obra y artífice del medio que lo rodea, el cual le da sustento material y le brinda la oportunidad de desarrollarse intelectual, moral, social y espiritualmente", explicitando los dos aspectos del medio humano: natural y cultural. Es decir que la calidad de vida y el ambiente "sano" y "equilibrado" son concebidos como derechos humanos.

La Conferencia de Río sobre el Medio Ambiente y el Desarrollo, en 1992, retoma los principios de Estocolmo que son lentamente incorporados en las constituciones reformadas en la década del 90, tal como ha sucedido en la Argentina en la noción de ambiente del art. 41. Este acercamiento entre lo cultural y lo ambiental ha recorrido un camino de más de 20 años para considerar la calidad de vida humana en el territorio. De ahí que se lo protege como consumidor y se resguardan los valores espirituales y culturales intrínsecamente ligados a la dignidad de su existencia para lo cual es necesaria la participación en las tres modalidades contempladas por el PIDESC (Pacto Internacional de Derechos Económicos, Sociales y Culturales).

El jurista argentino Lorenzetti (2009) ha desarrollado una teoría general ambiental donde propone pensar el ambiente como un macro bien, es decir, un sistema en el cual se interrelacionan diversos componentes o micro bienes: fauna, flora, agua, paisaje, bienes culturales. Este acercamiento entre lo cultural y lo ambiental ha recorrido un camino de más de 20 años hasta su reconocimiento constitucional, pues lo que se trata de proteger, en definitiva, es la calidad de vida humana en el territorio. De ahí que se lo protege como consumidor y se resguardan los valores espirituales y culturales intrínsecamente ligados a la dignidad de su existencia.

En este siglo XXI, los conflictos ya no son solamente interindividuales sino colectivos, por lo tanto, ya no hay sólo derechos sino también deberes tendientes a la protección de los bienes de uso y disfrute colectivo, como los bienes culturales. Acuerdos internacionales, 


\section{G. CISELLI et al.}

declaraciones y planes de acción han subrayado la importancia y la necesidad de avanzar hacia el desarrollo sustentable a través de una mayor participación ciudadana, apuntando especialmente al rol de las organizaciones no gubernamentales (Ryan, 2001).

\section{METODOLOGIA}

En primer término, se relevó la normativa internacional, nacional, provincial y local para mostrar la integralidad del sistema jurídico argentino al momento de tener que interpretar la normativa patrimonial. Esto significa que se partió del reconocimiento de la Constitución Nacional como la norma fundamental que debe respetarse en todos los niveles de gobierno y en el caso particular del patrimonio cultural debe complementarse con normativas locales que amplíen el piso de protección.

En segunda instancia se abordó la producción legislativa municipal (Cuadro 1) teniendo en cuenta la influencia que el sistema normativo nacional ha tenido en la labor legislativa como así también las recomendaciones y guías de los organismos internacionales. Para facilitar la interpretación de la misma se optó por una periodización que tomó como punto de partida el año 1985, fecha de sanción de la primera Ordenanza del Municipio de Comodoro Rivadavia referida al patrimonio cultural, para avanzar en dos etapas más vinculadas a dos momentos en que las normas aparecen, son apropiadas por los actores no estatales quienes demandan por la efectivización de las mismas al Estado.

En este proceso legislativo municipal se crean normas de aplicación general al patrimonio cultural y otras de aplicación específica que afectan en particular a cinco barrios de la ciudad y a sus habitantes. En este escenario se encuentran dos actores: el Estado Municipal por un lado que "hace”, "toma decisiones" y los vecinos individualmente o en grupos, organizaciones civiles, instituciones como la universidad que se unen en las demandas, que "exigen” por sus derechos reconocidos que requirió de la realización de un trabajo de campo en los barrios declarados como patrimonio.

Desde el enfoque etnográfico se buscó conocer las opiniones y percepciones que los actores no estatales tenían del patrimonio de sus barrios y en qué medida la existencia de la normativa municipal respondía a sus demandas teniendo en cuenta los desafíos que genera el patrimonio cultural tanto a las comunidades como a los gobiernos locales. Para ello se realizaron entrevistas en profundidad a referentes barriales acerca del significado de sus edificios, lugares y objetos para su vida y su barrio (vinculado a la noción de identidad) y al sentido de defenderlos ante riesgos de venta o destrucción, a las posibilidades de que estos formen parte de circuitos turísticos o de turismo cultural por el valor que tienen tanto desde un punto de vista material (económico) como simbólico (espiritual) ligado a sus propias vidas.

Del trabajo de campo en los distintos barrios declarados como patrimonio cultural en el año 2014 se recuperaron aquellos testimonios que daban cuenta de los atributos o criterios de valoración de las propias comunidades barriales en su mayoría vinculadas a sus 
historias laborales y a su vida cotidiana que promovieron la sanción de las Ordenanzas y una vez promulgadas, relacionados con su implementación. A continuación, se han seleccionado algunas de esas afirmaciones:

"Fue un barrio construido por Y.P.F. para su gente, con todas las comodidades, proveeduría, club, administración, hospital etc.”

"Ha sido lamentable a través de las distintas administraciones municipales y provinciales, que, a pesar de tener espacios de patrimonio histórico, han impactado al barrio con el argumento del crecimiento, como si no hubiera lugar en la ciudad para crecer".

"El Parque Saavedra: Es un lugar de recreación dónde la gente puede pasar un día de campo y a disfrutar del poco espacio verde que hay en la ciudad. Siempre fue muy renombrado, tal vez porque allí estuvo el primer zoológico de Comodoro Rivadavia y además porque ofrece un paisaje totalmente distinto".

"La comunidad no solo debe, sino, que tiene que participar en la elección, los habitantes son los que los ven a diario, desde su niñez, son parte del paisaje, son quienes los quieren, los protegen y de alguna manera buscan perpetuarlos en el tiempo, son parte de su identidad".

"Con las lluvias se dañó el edificio de la ex administración de Astra, pero como es patrimonio, necesitamos que la Comisión Evaluadora apruebe cualquier intervención”.

La mirada interdisciplinaria del equipo de trabajo facilitó el abordaje de diversos aspectos dando cuenta de la interrelación de la normativa con el saber de las comunidades respecto a ella y de los modos en que ésta afecta la calidad de vida de la población en los barrios. Asimismo, cómo la apropiación del conocimiento legal facilita la participación de los actores no estatales involucrados en la defensa del patrimonio de la ciudad.

\section{El Patrimonio Cultural desde un enfoque de Derechos Humanos}

La Constitución Nacional reformada en 1994 al incorporar tratados internacionales de derechos humanos, consagrar a los derechos colectivos como "nuevos derechos" y reconocer las autonomías municipales se convirtió en el marco normativo clave para el estudio del patrimonio cultural. Desde entonces el catálogo de derechos humanos se ha ampliado como así también las garantías reconocidas por el Estado en sus diversos niveles de gobierno.

Este enfoque de derechos humanos asumido por nuestro país al incluir el Pacto Internacional de Derechos Económicos, Sociales y Culturales (PIDESC) influye, o tendría que influir, en el diseño y la implementación de políticas públicas tanto a nivel nacional como local (Balardini \& Royo, 2012). En su artículo 15 inc. a) "Derecho de toda persona a participar en la vida cultural” y en la Observación general No 21 del Comité PIDESC (del año 2009) 


\section{G. CISELLI et al.}

aparecen criterios para efectivizar ese derecho por parte de los Estados. Asimismo, coloca en cabeza de las comunidades y las asociaciones culturales una responsabilidad fundamental en la promoción del derecho de toda persona a participar en la vida cultural a nivel local y nacional, así como en la cooperación con los Estados parte.

Un abordaje hermenéutico nos posibilita plantear la correlación existente entre los artículos 12 del PIDESC y 41 de la Constitución Nacional en cuanto a la inclusión del patrimonio cultural en la noción amplia de ambiente y en la consideración del derecho de todo habitante al ambiente sano, es decir, al más alto disfrute de salud física y mental. El artículo 41 señala, además, las funciones estatales obligatorias, entre las que se encuentra “proveer a la preservación del patrimonio cultural y natural...”. La palabra preservar proviene del latín praeservare, prefijo prae que significa delante y servare que alude a observar, prestar atención o cuidar en forma anticipada con el objetivo de evitar un eventual perjuicio o deterioro. Esta acción que implica tanto mantener intacto como proteger, incluye dos tipos de preservación: la preventiva y la correctiva cuya diferencia está en el momento que se actúa: antes o después que el bien patrimonial se vea afectado.

En el año 2003 Argentina ratificó el Protocolo Adicional a la Convención Americana sobre Derechos Humanos en materia de DESC o "Protocolo de San Salvador" que representa, un mandato de efectivización de esos derechos para los Estados y de garantías para los ciudadanos. Este instrumento jurídico, de carácter vinculante para la defensa de los derechos culturales de los ciudadanos en el marco del sistema interamericano de derechos humanos, exige de la medición del cumplimiento de los objetivos planteados en el Protocolo (Abramovich \& Pautassi, 2009). Por tal motivo se creó un Grupo de Trabajo, operativo desde 2010, que elaboró un sistema de indicadores de progreso que permitiera el análisis de los Informes presentados por los Estados Parte y agrupó en dos a los derechos contemplados en dicho Protocolo. Un primer documento fue aprobado por Resolución 2666 de la Asamblea General de la Organización de Estados Americanos en diciembre de 2011 y el segundo aprobado por Resolución 2798 en octubre de 2013 (Grupo de Trabajo, 2015). En particular interesa el documento de 2013 referido al segundo agrupamiento de derechos dado que contempla los derechos culturales (art. 14 PSS).

El artículo 14 del Protocolo, al referirse a las obligaciones de los Estados partes, reconoce tres derechos: "el derecho de toda persona a: a) Participar en la vida cultural y artística de la comunidad; b) gozar de los beneficios del progreso científico y tecnológico y c) beneficiarse de la protección de los intereses morales y materiales por ser autor de producciones científicas literarias y artísticas”.

En la Observación General No 21 del Comité PIDESC se encuentran algunos criterios interpretativos respecto del art 14, inc. a. en cuanto a los términos "participar" o "tomar parte”. El Comité sostiene que pueden ser/son utilizados indistintamente y refiere a tres modos relacionados entre sí: a) la participación en la vida cultural; b) el acceso a la vida cultural, c) la contribución a la vida cultural. 
La plena realización del derecho de toda persona a participar en la vida cultural requiere de la existencia de los siguientes elementos:

a) y b) La disponibilidad y la accesibilidad relacionadas con el disfrute y la información/ comunicación

c) La aceptabilidad de leyes, políticas, estrategias, programas y medidas adoptadas relacionadas con el disfrute de los derechos culturales que sean aceptables para las personas y las comunidades de que se trate para lo cual se deben celebrar consultas con esas personas y comunidades.

Los Estados partes tienen además la obligación de:

a) Respetar y proteger el patrimonio cultural en todas sus formas.

b) Promulgar legislación adecuada y el establecer mecanismos efectivos que permitan a las personas, individualmente, en asociación con otros o dentro de una comunidad o grupo, participar efectivamente en los procesos de adopción de decisiones, reivindicar la protección de su derecho a participar en la vida cultural, y reclamar y obtener una indemnización si se han infringido sus derechos. Este último punto se conecta con la legitimación amplia que existe para actuar en defensa de los bienes colectivos y que se encuentra prevista en el art. 43 de la Constitución Nacional.

En 2011, al ratificar el Protocolo Facultativo al PIDESC, vigente desde 2013, el Estado aporta una nueva herramienta para la exigibilidad y justiciabilidad de estos derechos al habilitarse una nueva vía para tratar casos individuales de violaciones de derechos previstos en el Pacto. Es decir, que el Comité tendrá competencia para analizar reclamos concretos de personas o grupo de personas que se hallen bajo la jurisdicción de un Estado que lo haya ratificado (Banus et al. 2013).

El marco jurídico vigente a nivel nacional sirvió como marco interpretativo para la generación de ordenanzas municipales acordes con las responsabilidades emanadas de la norma fundamental. En el cuadro 1 se visualizan las etapas del proceso de construcción del régimen jurídico del patrimonio cultural local estrechamente relacionado con el soft law y la normativa internacional y nacional.

\section{El Patrimonio Cultural y su protección municipal}

El municipio, particularmente desde el reconocimiento constitucional de su autonomía, es el responsable originario de las políticas urbanas y de la producción de sus reglas jurídicas. En el caso de Comodoro Rivadavia, aún antes del mandato constitucional, comenzó a legislar sobre los recursos culturales locales. 


\section{G. CISELLI et al.}

Tabla 1. Etapas en la producción normativa local y su relación con la normativa internacional y nacional.

\begin{tabular}{|c|c|c|c|}
\hline Etapas & Internacional & Nacional & Local \\
\hline $\begin{array}{l}\text { Primera: } 1985- \\
1998\end{array}$ & $\begin{array}{l}\text {-PIDESC } \\
\text {-Conferencia de Río sobre Medio } \\
\text { Ambiente y el Desarrollo }\end{array}$ & $\begin{array}{l}\text { Reforma Constitución } \\
\text { Nacional en } 1994\end{array}$ & Ordenanza $N^{\circ} 2625 / 85$ \\
\hline $\begin{array}{l}\text { Segunda: 1999- } \\
2014\end{array}$ & $\begin{array}{l}\text {-Carta de Nizhny Tagil sobre } \\
\text { Patrimonio Industrial (TICCIH) } \\
\text {-Observación No } 21 \text { Comité } \\
\text { PIDESC } \\
\text { Protocolo de San Salvador }\end{array}$ & $\begin{array}{l}\text { Ratificación del } \\
\text { Protocolo por } \\
\text { Argentina }\end{array}$ & Ordenanza N ${ }^{\circ} 6629 / 99$ \\
\hline $\begin{array}{l}\text { Tercera desde } \\
\text { junio } 2014\end{array}$ & & & $\begin{array}{l}\text { Ordenanzas } \mathrm{N}^{\circ} \\
11501 / 2014 \\
-11533 / 2014 \\
-12087 / 2016\end{array}$ \\
\hline
\end{tabular}

Fuente: elaboración propia

- Primera etapa: 1985-1998

En 1985 crea la Comisión Evaluadora del Patrimonio Histórico, Cultural y Natural (CEPHCyN) de la Ciudad como asesora del gobierno local e integrada por un grupo de expertos "ad honorem" provenientes de tres instituciones: Universidad, Colegio Arquitectos/Ingenieros y del propio Municipio. Durante esta etapa la Comisión no cuenta con normativa específica por lo que sólo elabora un primer listado de bienes a proteger que fueron seleccionados en base a los criterios de los profesionales que la componían en ese momento.

- Segunda etapa: 1999-2014

En el año 1999 se visualiza un avance normativo en el campo patrimonial que coincide con el reconocimiento constitucional y la entrada en vigor del Protocolo de San Salvador a nivel internacional. Por un lado, la Carta Orgánica le dedica dos capítulos y por otro, por Ordenanza 6629 se crea el Registro permanente de edificios, sitios y objetos del patrimonio histórico, cultural y natural.

El capítulo II de la Carta Orgánica titulado "Derechos y deberes de los vecinos hace referencia en el art. 14 in 1 al "derecho ...a la cultura..." y en el art. 16 inc. 4 al deber de “conservar y proteger los intereses y el patrimonio histórico cultural de la ciudad”. En el capítulo III titulado "Políticas especiales" tendientes a una mejor calidad de vida se le otorga al Municipio, en su art 30 incisos 3 y 4, la facultad de "Proyectar, concertar y ejecutar acciones 
de renovación y preservación de áreas y componentes del patrimonio histórico, urbano, arquitectónico, arqueológico y paisajes de la Ciudad, y reconocer su carácter de patrimonio colectivo de la comunidad" y "Promover acciones tendientes a preservar, valorizar y renovar los espacios representativos de la identidad de la ciudad". De acuerdo con lo previsto en el Inc. 6 del mismo artículo 30, es facultativo del Municipio "instrumentar mecanismos de participación y consulta ...en acciones de significación urbana”.

El art. 31 está dedicado al ambiente "El Municipio procura para los vecinos un ambiente sano y equilibrado que asegure la satisfacción de las necesidades presentes, sin comprometer las de generaciones futuras. Desarrolla una política de planeamiento y gestión del ambiente urbano integrada a las políticas de desarrollo económico, social y cultural. Instrumenta un proceso de ordenamiento territorial y ambiental participativo y permanente".

En el art. 33 (COM), referido a la identidad y el desarrollo cultural, propone la actitud colaborativa entre "los Poderes públicos y la comunidad, en reconocimiento de la identidad cultural de la Ciudad de Comodoro Rivadavia [...] que contribuyen al desarrollo cultural de la Ciudad, preservan y difunden el Patrimonio Cultural y Natural, favorecen su accesibilidad social, fomentan la creación, producción y circulación de bienes culturales, promueven la participación colectiva, el pluralismo y la libertad de expresión".

Es decir que, interpretando conjuntamente los arts. 30, 31 y 33, en la elaboración de políticas públicas especiales y el artículo 46 donde explícitamente "El Municipio promueve la formación de entes vecinales, organizaciones intermedias y no gubernamentales que actúen en la satisfacción de necesidades culturales, educativas, artísticas y sociales en general, mediante la iniciativa privada, el voluntariado, el padrinazgo y toda otra modalidad de participación" se puede plantear la recepción de derechos en el plano normativo local vinculado a las nociones: identidad, calidad de vida, derechos, participación.

La Ordenanza 6629 que crea el Registro permanente (aún vigente, pero en proceso de revisión) prevé que, a partir de una investigación preliminar que requiere la utilización de encuestas, relevamientos gráficos, cartográficos, fotográficos y observaciones directas, la Comisión Evaluadora elabore una ficha de inventario por bien. Además de proponer criterios de orden histórico-cultural; artístico-arquitectónico y paisajístico-ambiental para la selección de bienes, el legislador propuso el trabajo interdisciplinario y la "participación comunitaria" en su detección. En la práctica la participación en la selección de bienes ha sido limitada y sólo en la última década ha comenzado a ejercitarse.

Desde sus inicios, la Comisión Evaluadora ha actuado mayormente de oficio en la selección de bienes y en la elaboración de un dictamen, aunque también lo ha hecho a partir de sugerencias de las Asociaciones Vecinales, a pedido de otra dirección del Estado Municipal, del Concejo Deliberante, de la Comisión Nacional de Monumentos, Lugares y Bienes históricos para proponer declaratorias por adhesión, conectadas con otras a nivel nacional. A partir de ambos marcos normativos (Ord. 2625/85 y 6629/99), la CEPHCyN elaboró un primer Listado de Bienes en 1989. 


\section{G. CISELLI et al.}

En Comodoro Rivadavia, el contexto donde se inicia la problematización de la cuestión patrimonial, está marcado por el sentido de pertenencia construido en torno a la empresa Y.P.F., social y espacialmente localizado en el Barrio General Mosconi y en aquellos lugares que fueron de uso exclusivo por los ypefeanos hasta la privatización de los años noventa cuando "sus bienes" fueron transferidos al Estado municipal, a la Universidad local o a la Provincia con diversos fines. Si bien con la universidad no hubo conflictos, estos aparecieron cuando el municipio comenzó a decidir qué destino darles y bajo qué modalidades jurídicas. Desde el año 2002 la Comisión acompañó propuestas de vecinos respecto de la recuperación y revitalización de los barrios con pasado industrial, particularmente aquellos afectados por la privatización de Y.P.F. En ese marco realizó un inventario de bienes, sitios y objetos vinculados al campamento central de la empresa petrolera estatal para proponer un recorrido turístico y desde 2009 comenzó a discutirse la Declaratoria del barrio General Mosconi como patrimonio cultural de la ciudad.

En uno de esos barrios creados por Y.P.F. es donde se identifica una primera manifestación en el año 2006 cuando una vecina presenta una acción de amparo ante la entrega en comodato del Parque Saavedra (construido por la empresa estatal en 1937) al Sindicato del Centro de Empleados de Comercio con el argumento que pone en riesgo su valor como "patrimonio cultural, histórico y paisajístico", acción admisible, pero con sentencia adversa fundado por el juez en que no existía declaratoria formal, por lo tanto, no merecía protección (Ciselli, 2012). La siguiente gestión municipal lo declara patrimonio cultural de la ciudad en 2008, "habilitando" una movilización de las organizaciones civiles y vecinal del barrio General Mosconi y Saavedra en contra de las obras que estaba realizando el ente gremial ocurrida a fines de 2009 y el planteo de la declaratoria del Barrio General Mosconi como patrimonio de la ciudad.

Lo antedicho permite dar cuenta que algunos actores no estatales se fueron consolidando a partir de acciones que "afectaban su calidad de vida y su patrimonio cultural”. Esta construcción social del "gran patrimonio ypefeano" continuó fortaleciéndose con el tiempo, impulsando nuevas movilizaciones durante los años 2013 y 2014. En mayo de 2013, la prensa hizo público que la Municipalidad -el Poder Ejecutivo- había presentado una oferta de seis millones de pesos para la compra del edificio del sindicato SUPEH (antes se lo había vendido) y que había sido aceptada por éste. Según publicó Diario El Patagónico, la venta fue avalada por una asamblea convocada el 23 de diciembre de 2012 a la que supuestamente asistieron 18 afiliados (posteriormente se confirmó que podían superar los 200). La operación inmobiliaria, avalada por el Concejo Deliberante -por Ord. 11002/13- implicaba la derogación de la Ordenanza del 2002 -que protegía el uso del espacio verde y de recreación de dicho edificio- que por más de cincuenta años fue lugar de encuentro para los trabajadores y espacio vivencial y cotidiano para muchos niños y abuelos que iban a la plaza a compartir los juegos y que a fines de los 80 y los 90 fue uno de los focos de resistencia a la privatización de la empresa estatal. Ante el escándalo, el intendente vetó la Ordenanza y concejales junto con 
vecinos presentaron una denuncia por presunta estafa en la compraventa y la falsificación de firmas en las Actas de la Asamblea de 2012. En forma simultánea, los vecinos del barrio se encontraron para acordar un plan de acción. Entre el 15 y el 30 de junio de 2013 la Asociación Vecinal General Mosconi invitó a los residentes del barrio y habitantes de Comodoro Rivadavia a reunirse en la plaza y emprender una campaña de recolección de firmas por el "No al cierre de la plaza SUPeH".

Casi en forma paralela al proceso anterior, la Asociación Vecinal promovió otra acción popular en defensa de un espacio verde dentro del Barrio General Mosconi. Eran 32 hectáreas de tierras, paralelas a la Ruta Nacional o 3, que fueran cedidas al Estado Nacional por la ex Compañía de Comunicaciones 9 y uno de los predios más requeridos para proyectos urbanísticos y comunitarios. En 2013 apenas comenzado el movimiento de suelo en el lugar, la Vecinal elevó un escrito al municipio, solicitando la transferencia de dichas tierras al ámbito municipal con afectación exclusiva a la creación de un "Parque para la ciudad" prometido en 2007. El petitorio tuvo respaldo de más de 5.000 firmas y se solicitó al Concejo Deliberante que diera continuidad al trámite para la obtención de la declaratoria, como área de Patrimonio Cultural, al barrio General Mosconi de Kilómetro 3.

Como una manera de descomprimir la "tensión territorial", el Concejo Deliberante sancionó la Ordenanza 11.501 en 2014 declarando al Barrio General Mosconi como Patrimonio Cultural.

- $\quad$ Tercera etapa: desde junio 2014

Las acciones colectivas, comentadas en el apartado anterior, actuaron como recursos frente al Estado Municipal que no sólo retrocedió en sus decisiones, sino que actuó positivamente a partir de ellas. Por un lado, derogando la Ordenanza en que se comprometía a la compra del predio de SUPeH y dando un paso atrás con la construcción de un plan de viviendas en tierras prometidas para dicho espacio verde y de uso público. Por otro, declarando no sólo al Barrio General Mosconi sino también a otros barrios históricos vinculados al pasado industrial petrolero y ferroviario de la ciudad como Patrimonio Cultural de la ciudad (Ciselli, 2015).

La Ordenanza 11501, promulgada el 5 de junio de 2014, encomienda: inventariar y señalizar los bienes culturales y naturales de los cinco barrios declarados (barrios Gral. Mosconi, $\mathrm{Km}$ 5, Km 8, Astra y Diadema); elaborar normativa para su preservación e incorporarlos en un circuito turístico cultural.

En tiempo récord, un mes más tarde, la Ordenanza 11533 era sancionada. A casi treinta años de la norma que creaba a la Comisión, sus actuales miembros plantearon la necesidad de actualizarla, acorde con el mandato constitucional y enmarcada en el sistema jurídico ambiental. En ella se reconoce a la nueva Comisión Evaluadora como asesora no sólo del poder ejecutivo sino también del legislativo municipal y que sus dictámenes son vinculantes. 


\section{G. CISELLI et al.}

En pos de su cumplimiento se amplían las funciones en lo referente a la protección, gestión e intervención del patrimonio, especialmente arquitectónico/edificado- y en la coordinación de acciones tendientes a la participación ciudadana para la detección y selección de bienes que sean considerados significativos por la propia comunidad. Las pugnas entre el interés del desarrollo inmobiliario y el interés colectivo forman parte de este nuevo desafío, ya que las decisiones respecto a las declaratorias siguen siendo políticas

En la norma actualizada se contemplan nuevos criterios de valoración y concepciones de la gestión del patrimonio en la ciudad que toman como antecedente principios y guías provenientes de organismos internacionales vinculados a la cultura. El soft law ha tenido influencia en la preservación, conservación, gestión e intervención del patrimonio por la vía de los expertos o técnicos en patrimonio e incluso a través de las Recomendaciones de ICOMOS Argentina.

El artículo 4 inciso e) explicita entre las funciones de la Comisión la de "Coordinar las acciones tendientes a la participación ciudadana para la detección y selección de bienes que sean considerados significativos por la propia comunidad". En los considerandos del Listado de Bienes aprobado por Ordenanza 12087 de 2016 que eleva la Comisión al Concejo aparecen dos cuestiones relevantes para el tema que estamos tratando: el compromiso y la participación ciudadana. La Comisión advierte que "en los últimos tiempos ha registrado el reclamo de vecinos preocupados por la conservación de bienes significativos para su historia e identidad" y que "El presente listado será ampliado por evaluación de la Comisión o a pedido de particulares, Asociaciones Vecinales y/o instituciones”.

La sanción de ambas Ordenanzas brindaba un nuevo campo de estudio para la preservación del patrimonio cultural. No hay que olvidar que, desde la Reforma de 1994, en Argentina, son los municipios quienes asumen la prestación de servicios, el cuidado del ambiente y también la protección, gestión e intervención del patrimonio.

\section{CONCLUSIONES}

Las cuestiones patrimoniales urbanas exigen de miradas interdisciplinarias que permitan interpretar situaciones que acontecen en la ciudad penetradas por la multidimensionalidad y la lógica de la multiplicidad de actores. Frente al conjunto de la ciudad, el barrio es el espacio urbano de lo cotidiano donde existen modos de sociabilidad activa construidos con el paso del tiempo. En ese "territorio histórico", en esos espacios apropiados y valorizados colectivamente es donde se construyen las identidades sociales urbanas a partir de la puesta en valor de sus bienes patrimoniales.

En Argentina, las cualidades del patrimonio cultural que remiten a la calidad de vida de la población lo han colocado en un lugar de privilegio al ubicarlo, en el artículo 41, como un derecho/deber constitucional intergeneracional que incluye a todos (autoridades, ciudadanos o habitantes o dicho de otro modo actores estatales y no estatales) en la obligación de 
preservarlo. Ello se debe, además, a que es considerado un bien colectivo, testimonio material y simbólico de una cultura y elemento identitario para la comunidad que lo protege.

El Estado, a través del diseño de políticas públicas, debe intervenir en el territorio generando espacios destinados a la vida cultural. El marco jurídico internacional brinda herramientas conceptuales y metodológicas que constituyen guías para la acción en las distintas dimensiones del campo cultural que contribuyen al efectivo cumplimiento de dichos derechos.

Los municipios, y en el caso analizado el de Comodoro Rivadavia, tienen reconocida su autonomía para actuar en el micro-territorio y convertir la noción de patrimonio en un instrumento para el desarrollo local al reconocer el valor de ciertos espacios, edificios y objetos considerados de valor patrimonial, tal como lo ha demostrado a través de la sanción de la Ordenanza 11501 en 2014 que declaró cinco barrios de la ciudad con pasado industrial. Una Ordenanza que planteó desafíos a la comunidad.

Cuando la Ordenanza propone inventariar y señalizar los bienes culturales genera la posibilidad que la comunidad barrial participe en la selección de los bienes que consideran significativos por lo cual, en forma indirecta, fortalece las identidades socio-territoriales. El reconocimiento de que ciertos edificios o sitios que forman parte de la vida cotidiana puedan ser objeto de protección lleva intrínseca la idea de sostenibilidad lo que redundará en beneficio de las generaciones futuras.

La interpretación de las Ordenanzas Municipales 6629/99, 11501, 11533/2014 y 12087/2016 a la luz de un enfoque de derechos humanos brinda un nuevo campo de acción para los ciudadanos en torno a la preservación del patrimonio cultural de su microterritorio. No hay que olvidar que, desde el reconocimiento de las autonomías municipales en la Reforma de 1994, en Argentina son los gobiernos locales quienes asumen la prestación de servicios, el cuidado del ambiente y también la protección, gestión e intervención del patrimonio local. La preservación de los bienes declarados, a través de una normativa específica e integral a la vez, y el respeto por el derecho a participar en la vida cultural influyen sobre la calidad de vida de quienes habitan el suelo argentino.

Por último, el mandato de incorporar a los barrios declarados dentro de un circuito turístico cultural coincide con los modelos de gestión local y estrategias de vinculación del Municipio con los barrios constituyendo una oportunidad para los micro-emprendedores y para la generación de recursos genuinos a partir del fomento al turismo. Cada vez más los viajeros y los lugareños se muestran interesados en aquellos sitios que ofrecen información sobre el pasado de la región o la ciudad complementando lo lúdico con el ocio creativo.

\section{REFERENCIAS}

Abramovich, V., \& Pautassi, L. (2009). El enfoque de derechos y la institucionalidad de las políticas sociales. En V. Abramovich \& L. Pautassi (Comp.), La revisión judicial de las 


\section{G. CISELLI et al.}

políticas sociales. Estudio de casos. Buenos Aires: Editores del Puerto.

Balardini, L., \& Royo, L. (2012). La exigibilidad del derecho a la Vivienda y el uso de indicadores para su monitoreo. Las relocalizaciones en la Cuenca Matanza Riachuelo. En L. Pautassi \& G. Gramallo (Comps.), ¿Más derechos, menos marginaciones? Políticas sociales y bienestar en la Argentina. Buenos Aires: Editorial Biblos.

Banus, L., Adler, F., Massari, L., \& Murad, A. (2013). Breve reflexión en torno al nuevo Protocolo Facultativo al Pacto de Derechos Económicos, Sociales y Culturales. Recuperado de: www.infojus.gov.ar Id SAIJ: DACF130128

Brac, M. (2011). Patrimonio cultural y turismo emergente. Villa Guillermina, de pueblo obrero a nuevo destino turístico. Un estudio de caso. Cuadernos de Antropología Social, Facultad de Filosofía y Letras, 33, 111-128.

Carta de Nizhny Tagil sobre Patrimonio Industrial, Rusia, 2003, TICCIH. Recuperado de: https://www.icomos.org/18thapril/2006/nizhny-tagil-charter-sp.pdf

Ciselli, G. (2012). El parque Saavedra como paisaje cultural protegido. En V. Navarro \& S. Espinosa (Comps.), Paisajes culturales: Memorias de las Jornadas de reflexión acerca de los paisajes culturales de Argentina y Chile, en especial los situados en la región Patagónica. Río Gallegos: UNPA.

Ciselli, G. (2014). El patrimonio cultural: debates actuales y múltiples miradas. Comodoro Rivadavia bajo el prisma patrimonialista. Comodoro Rivadavia: Ed. Vela al Viento.

Ciselli, G. (2015). El patrimonio cultural: su reconocimiento constitucional y su apropiación social. En G. Ciselli \& M. Hernández (Comps.), El patrimonio industrial petrolero como la huella del trabajador en el territorio. El caso de Y.P.F. en Comodoro Rivadavia y su impronta cultural (pp. 27-51). Buenos Aires: Ed. Dunken.

Ciselli, G., \& Duplatt, A. (Comps.) (2006). KM 5: Barrios patagónicos con memoria petrolera y ferroviaria. Buenos Aires: Editorial Dunken.

Ciselli, G., \& M. Hernández, M. (2015). El patrimonio cultural como la huella del trabajador petrolero en el territorio. Buenos Aires: Ed. Dunken.

Ciselli, G., \& A. Enrici (2016). En torno al valor histórico paisajístico del patrimonio cultural. En A. Enrici, G. Ciselli \& R. Firpo. Arte y filosofía (pp. 63-85). Río Gallegos: UNPAedita.

Ciselli, G., \& Hernández, M. (2017). Historia, memoria colectiva e identidad. En G. Ciselli \& M. Hernández. Memoria petrolera y paisaje industrial (pp. 103-115). Comodoro Rivadavia: Ed. Biblioteca Popular Astra.

Ciselli, G., \& Hernández, M. (2015). El derecho constitucional al patrimonio cultural. La movilización ciudadana como recurso frente al Estado Municipal. En G. Ciselli \& M. Hernández (Comps.), El patrimonio industrial petrolero como la huella del trabajador en el territorio. El caso de Y.P.F. en Comodoro Rivadavia y su impronta cultural (pp. 99125). Buenos Aires: Ed. Dunken.

Delgadillo Polanco, V. (2010). La dimensión económica del patrimonio cultural. Andamios, 7(14), 385-389. 
Comité De Derechos Económicos, Sociales Y Culturales, Observación General No 21, Derecho de toda persona a participar en la vida cultural, E/C.12/GC/21/Rev. 1, 17 mayo de 2010 Duplatt, A. (2017). Las políticas patrimoniales: del municipio al barrio. En G. Ciselli \& M. Hernández. Memoria petrolera y paisaje industrial (pp. 25-44). Comodoro Rivadavia: Ed. Biblioteca Popular Astra.

Duplatt, A., Ciselli, G., \& Hernández, M. (2016). El paisaje industrial petrolero como expresión de la cultura territorial en la Cuenca del Golfo San Jorge. En V. NavarroG. Ciselli (Comp.), Paisajes Culturales y Patrimonio: expresiones de la cultura territorial. Río Gallegos. UNPA. Recuperado de www.repotur.gov.ar/handle/123456789/7008

Figueroa, M., \& Galleguillo, N. (2015). Circuitos turísticos patrimoniales: un recorrido por los lugares y por la memoria. En G. Ciselli \& M. Hernández (Comps.), El patrimonio industrial petrolero como la huella del trabajador en el territorio. El caso de Y.P.F. en Comodoro Rivadavia y su impronta cultural (pp. 277-286). Buenos Aires: Ed. Dunken.

García Canclini, N. (1993). Los usos sociales del patrimonio cultural. En E. Florescano (Comp.), El Patrimonio Cultural de México. México: Fondo de Cultura Económico.

Gravano, A. (2005). El barrio en la teoría social. Buenos Aires: Espacio Edit.

Gravano, A. (2003). Antropología de lo barrial. Estudios sobre producción simbólica de la vida urbana. Buenos Aires: Espacio Edit.

Gravano, A. (2013). Antropología de lo urbano. Tandil: UNICEN.

Grupo de Trabajo Protocolo de San Salvador (2015). Indicadores de progreso para medición de derechos contemplados en el Protocolo de San Salvador. GT para el análisis de los Informes nacionales del Protocolo de San Salvador. Organización de Estados Americanos (OEA), Washington D.C.

Krebs, M., \& Schmidt-Hebbel, K. (s/f). Patrimonio cultural: aspectos económicos y políticas de protección. Perspectivas, 207-245.

Lorenzetti, R. (2009). Teoría del Derecho ambiental. Buenos Aires: La Ley.

Navarro Bello, G. (2003). Una aproximación al paisaje como patrimonio cultural, identidad y constructo mental de una sociedad. Apuntes para la búsqueda de invariantes que determinen la patrimonialidad de un paisaje. Revista Electrónica DU \& P Revista de Diseño Urbano y Paisaje, 1 (1).

Pérez Galán, B. (2011). Los usos de la cultura en el discurso legislativo sobre Patrimonio Cultural en España. Una lectura antropológica sobre las figuras legales de protección. Revista de Antropología Experimental, 11, 11-30.

Prats, L. (2006). La mercantilización del patrimonio: entre la económica turística y las representaciones identitarias. PH Boletín del Instituto Andaluz del Patrimonio Histórico, $58,72-80$.

Rodríguez, J. (1998). La Ciencia del Paisaje a la luz del paradigma ambiental. Revista Trimestral Geonotas, 2(1).

Ryan, D. (2001). Democracia participativa, ambiente y sustentabilidad. En Ecología de la 


\section{G. CISELLI et al.}

información: escenarios y actores para la participación en asuntos ambientales. Nueva Sociedad, FLACSO.

Throsby, D. (2001). Economía y Cultura. España: Cambridge University Press. 